\title{
Cytokine levels in pleural fluid as markers of acute rejection after lung transplantation*
}

\author{
Citocinas no líquido pleural após transplante pulmonar \\ como marcadores de rejeição aguda
}

\author{
Priscila Cilene León Bueno de Camargo, José Eduardo Afonso Jr, \\ Marcos Naoyuki Samano, Milena Marques Pagliarelli Acencio, \\ Leila Antonangelo, Ricardo Henrique de Oliveira Braga Teixeira
}

\begin{abstract}
Our objective was to determine the levels of lactate dehydrogenase, $1 \mathrm{~L}-6,1 \mathrm{~L}-8$, and VEGF, as well as the total and differential cell counts, in the pleural fluid of lung transplant recipients, correlating those levels with the occurrence and severity of rejection. We analyzed pleural fluid samples collected from 18 patients at various time points (up to postoperative day 4). The levels of $1 \mathrm{~L}-6,1 \mathrm{~L}-8$, and VEGF tended to elevate in parallel with increases in the severity of rejection. Our results suggest that these levels are markers of acute graft rejection in lung transplant recipients.
\end{abstract}

Keywords: Lung transplantation; Pleural effusion; Cytokines; Graft rejection.

\section{Resumo}

Nosso objetivo foi determinar os níveis de desidrogenase lática, lL-6. 1L-8 e VEGF, assim como a contagem total e diferencial de células no líquido pleural de transplantados de pulmão, correlacionando esses níveis com a ocorrência e a gravidade de rejeição após o procedimento. Foram analisadas amostras de líquido pleural coletadas de 18 pacientes em diferentes momentos (até o quarto dia pós-operatório). Os níveis de 1L-6, 1L-8 e VEGF apresentaram uma tendência de aumento paralelamente à gravidade de rejeição. Nossos resultados sugerem que esses níveis são indicadores de rejeição aguda do enxerto em transplantados de pulmão.

Descritores: Transplante de pulmão; Derrame pleural; Citocinas; Rejeição de enxerto.

Lung transplantation (LT) is a therapeutic option for patients with advanced lung disease. Despite advances in the treatment of lung transplant recipients, acute graft rejection remains common, affecting up to 55\% of all such patients in the first postoperative year. Rejection is the major risk factor for bronchiolitis obliterans syndrome and appears to be related to a humoral response with complement activation and production of donor-specific HLA antibodies. ${ }^{(1)}$ Transbronchial biopsy (TBB) is the primary method for diagnosing acute cellular rejection. Several studies have shown a correlation between elevated serum cytokine levels and postoperative complications, as well as an association of serum cytokine levels with reperfusion edema, acute rejection, and bronchiolitis obliterans syndrome. ${ }^{(2)}$ The objective of the present study was to determine whether acute cellular rejection correlates with lactate dehydrogenase (LDH) levels, proinflammatory cytokine levels, and differential cell counts in the pleural fluid of lung transplant recipients. We hypothesized that elevated levels of proinflammatory cytokines in the pleural fluid of lung transplant recipients are early indicators of graft rejection.

Between August of 2006 and March of 2008, 20 lung transplant recipients were evaluated for inclusion in the present study, 18 being included. Two patients were excluded from the analysis because they died within the first 6 weeks. The overall LDH levels, overall cytokine levels, and cell counts in pleural fluid were reported elsewhere, without any reference to rejection. ${ }^{(3)}$

*Study carried out in the Department of Pulmonology, Heart Institute, University of São Paulo School of Medicine Hospital das Clínicas, São Paulo, Brazil.

Correspondence to: Priscila Cilene León Bueno de Camargo. Avenida Dr. Enéas de Carvalho Aguiar, 44, $2^{\circ}$ andar, Bloco 2, Sala 9, Cerqueira César, CEP 05403-900, São Paulo, SP, Brasil.

Tel. 5511 2661-5248. E-mail: pclbcamargo@gmail.com

Financial support: None.

Submitted: 8 May 2014. Accepted, after review: 13 June 2014. 
Blood and pleural fluid samples were collected $6 \mathrm{~h}$ after surgery and daily until postoperative day 4. A TBB was performed at 2 and 6 weeks after LT in order to evaluate the severity of rejection, which was classified according to the intensity of perivascular mononuclear cell infiltration in the lung parenchyma, as follows: A0, no rejection; A1, minimal rejection; $A 2$, mild rejection; $A 3$, moderate rejection; and $\mathrm{A} 4$, severe rejection. For the final analysis, the highest degree of rejection was selected.

No TBB samples underwent blind analysis. All TBB procedures were performed by a trained pathologist as routinely done at our facility. At least 5 tissue samples were analyzed in order to ensure that the lung parenchyma was adequately represented.

$\ln 3,4,8$, and 3 of the 18 patients studied, the severity of rejection was classified as $A 0$, $A 1, A 2$, and $A 3$, respectively.
Serum levels of IL-6 and IL-8 were undetectable in all samples. Serum VEGF levels were much lower than pleural fluid VEGF levels and were not significantly different among subgroups $\mathrm{A} 0$, $\mathrm{A} 1, \mathrm{~A} 2$, and $\mathrm{A} 3$.

In the present study, undetectable serum cytokine levels suggest that the inflammatory response in lung transplant recipients is primarily confined to the lungs and pleural cavity. Similar results have been reported elsewhere, ${ }^{(2,4,5)}$ acute elevation of serum cytokine levels having been found to be more evident in patients with reperfusion edema or acute rejection.

The correlation between LDH levels and differential cell counts in pleural fluid is shown in Table 1, having been found to be higher in the subgroups of patients with graft rejection.

We found elevated levels of IL-6 and IL-8 in the pleural fluid samples collected $6 \mathrm{~h}$ after LT, those levels having decreased by postoperative day 4. No such variation was observed in VEGF

Table 1 - Relationship of the severity of acute rejection with the levels of lactate dehydrogenase, as well as with the total and differential cell counts, in pleural fluid samples collected at various time points. ${ }^{a}$

\begin{tabular}{|c|c|c|c|c|}
\hline \multirow[t]{2}{*}{ Variable } & \multicolumn{4}{|c|}{ Severity of acute rejection } \\
\hline & A0 & $\mathrm{A} 1$ & $\mathrm{~A} 2$ & A3 \\
\hline \multicolumn{5}{|l|}{$\mathrm{LDH}, \mathrm{mg} / \mathrm{dL}$} \\
\hline $6 \mathrm{~h}$ & $1,855 \pm 594$ & $3,176 \pm 530^{* *}$ & $2,310 \pm 964$ & $4,134 \pm 1,487^{*}$ \\
\hline $24 \mathrm{~h}$ & $1,250 \pm 1,028$ & $1,605 \pm 1,285$ & $1,779 \pm 1,233$ & $2,214 \pm 958$ \\
\hline $48 \mathrm{~h}$ & $1,181 \pm 293$ & $1,455 \pm 642$ & $966 \pm 503$ & $1,638 \pm 1,201$ \\
\hline $72 \mathrm{~h}$ & $375 \pm 46$ & $655 \pm 462$ & $576 \pm 159$ & $711 \pm 203^{* * * *}$ \\
\hline $96 \mathrm{~h}$ & $316 \pm 33$ & $586 \pm 434$ & $498 \pm 214$ & $621 \pm 233$ \\
\hline \multicolumn{5}{|c|}{ Total cells, cells/mL } \\
\hline $6 \mathrm{~h}$ & $1,679 \pm 1,612$ & $3,812 \pm 2,387$ & $4,606 \pm 3,156$ & $10,710 \pm 6,394^{* * * *}$ \\
\hline $24 \mathrm{~h}$ & $595 \pm 786$ & $2,764 \pm 1,250^{* * * * *}$ & $2,359 \pm 645^{* * * *}$ & $4,723 \pm 2,514^{* * * * * * * * * *}$ \\
\hline $48 \mathrm{~h}$ & $645 \pm 116$ & $897 \pm 626$ & $649 \pm 421$ & $2,457 \pm 2,180$ \\
\hline $72 \mathrm{~h}$ & $246 \pm 323$ & $316 \pm 168$ & $542 \pm 456$ & $599 \pm 680$ \\
\hline $96 \mathrm{~h}$ & $167 \pm 223$ & $418 \pm 288$ & $435 \pm 399$ & $482 \pm 120^{* * * *}$ \\
\hline \multicolumn{5}{|l|}{ Neutrophils } \\
\hline $6 \mathrm{~h}$ & $1,573 \pm 1,485$ & $3,580 \pm 2,281$ & $4,368 \pm 3,074$ & $9,884 \pm 5,245^{* * * * * *}$ \\
\hline $24 \mathrm{~h}$ & $537 \pm 707$ & $2,471 \pm 942^{* * * *}$ & $1,314 \pm 1,255^{* * * * *}$ & $4,478 \pm 2,553^{* * * * *}$ \\
\hline $48 \mathrm{~h}$ & $588 \pm 147$ & $812 \pm 642$ & $590 \pm 450$ & $2,266 \pm 2,255$ \\
\hline $72 \mathrm{~h}$ & $210 \pm 274$ & $266 \pm 155$ & $475 \pm 431$ & $374 \pm 393$ \\
\hline $96 \mathrm{~h}$ & $144 \pm 192$ & $258 \pm 252$ & $367 \pm 339$ & $235 \pm 195$ \\
\hline \multicolumn{5}{|l|}{ Lymphocytes } \\
\hline $6 \mathrm{~h}$ & $90 \pm 112$ & $161 \pm 56$ & $156 \pm 126$ & $1,078 \pm 1,455$ \\
\hline $24 \mathrm{~h}$ & $52 \pm 72$ & $136 \pm 140$ & $71 \pm 28$ & $191 \pm 74^{* * * *}$ \\
\hline $48 \mathrm{~h}$ & $45 \pm 32$ & $65 \pm 62$ & $48 \pm 50$ & $145 \pm 90^{* * *}$ \\
\hline $72 \mathrm{~h}$ & $36 \pm 50$ & $45 \pm 24$ & $36 \pm 4$ & $133 \pm 166$ \\
\hline $96 \mathrm{~h}$ & $23 \pm 32$ & $78 \pm 61$ & $41 \pm 43$ & $59 \pm 62$ \\
\hline
\end{tabular}

A0: no rejection; A1: minimal rejection; A2: mild rejection; A3: moderate rejection; and LDH: lactate dehydrogenase. aValues expressed as mean \pm SD. ${ }^{*} p<0.05$ (A3 > A0 and A2). ${ }^{* *} p<0.05$ (A1 > A0). ${ }^{* * *} p<0.05$ (A3 $\left.>A 0\right) .{ }^{* * * *} p<0.05$ $(\mathrm{A} 3, \mathrm{~A} 2$, and $\mathrm{A} 1>\mathrm{A} 0) .{ }^{* * * * *} \mathrm{p}<0.05$ (A3 > A1 and A2). ${ }^{* * * * *} \mathrm{p}<0.05$ (A3 > A0, A1, and A2). 
levels. Patients in whom graft rejection was more severe tended to have higher levels of those cytokines (Table 2). Patients in whom the severity of rejection was classified as A3 had higher levels of 1L-6 and 1L-8 at all time points when compared with those in whom graft rejection was less severe. In the samples collected $6 \mathrm{~h}$ after LT, VEGF levels were higher in the patients in whom the severity of rejection was classified as $\mathrm{A} 3, \mathrm{~A} 2$, or $\mathrm{A} 1$ than in those in whom it was classified as $\mathrm{A} 0$.

Inflammation of the pleural space is due to the surgical trauma and the presence of a chest tube and can explain the high levels of cytokines. In our study, it is of note that, although inflammatory marker levels progressively decreased over time, proinflammatory cytokine levels remained elevated during the first 4 days, and irritation caused by the chest tube left in place for up to $96 \mathrm{~h}$ can explain that, although it does not explain the differences among the subgroups of patients. We speculate that the cytokine levels found in the patients classified as A0 represent the increase in cytokine levels that occurs as a result of the surgical trauma and the use of chest tubes. This level of inflammation decreases over time, as evidenced by a reduction in pleural fluid levels of 1L-6 and 1L-8. The cytokine levels found in the patients in whom the severity of rejection was classified as A3 were much higher than were those found in the remaining subgroups of patients, and this might be an early indicator of rejection.

Pleural fluid levels of 1L-6 correlated positively with LDH levels $(r=0.49 ; p=0.030)$ and the neutrophil count $(r=0.90 ; p=0.036)$, and VEGF levels were strongly correlated with the neutrophil count $(r=0.91 ; p=0.030)$ and the total leukocyte count $(r=0.88 ; p=0.048)$. In contrast, a strong negative correlation was found between 1L-8 levels and the lymphocyte count ( $r=-0.97 ; p=0.007)$. In addition, a strong positive correlation was found between IL-6 levels and IL-8 levels ( $r=0.70 ; p<0.001)$, as well as between $1 \mathrm{~L}-6$ levels and VEGF levels $(r=0.71 ; p<0.001)$. Furthermore, there was a slight correlation between $1 \mathrm{~L}-8$ levels and VEGF levels $(r=0.49 ; p=0.027)$. In the present study, there was no correlation between the severity of acute rejection and the severity of primary graft dysfunction within the first $72 \mathrm{~h}$ after LT.

In lung transplant recipients, inflammation of the lung parenchyma leads to increased interstitial edema with increased cytokine levels. Because

Table 2 - Relationship of the severity of acute rejection with the levels of IL-6, IL-8, and VEGF in pleural fluid samples collected at various time points. ${ }^{\text {a }}$

\begin{tabular}{ccccc}
\hline Variable & \multicolumn{4}{c}{ Severity of acute rejection } \\
\cline { 2 - 5 } lL-6, pg/mL & A0 & A2 & A3 \\
$6 \mathrm{~h}$ & $14,717(10,719-18,816)$ & $27,368(20,445-41,316)$ & $38,521(29,543-45,367)$ & $49,854(42,854-53,415)^{*}$ \\
$24 \mathrm{~h}$ & $6,384(2,304-10,464)$ & $13,410(10,973-17,608)$ & $12,060(8,886-17,824)$ & $21,337(17,779-48,322)^{* *}$ \\
$48 \mathrm{~h}$ & $7,642(2,707-12,576)$ & $11,402(9,370-13,303)$ & $12,211(9,075-13,477)$ & $15,010(12,717-46,503)^{* *}$ \\
$72 \mathrm{~h}$ & $5,010(2,227-7,793)$ & $7,731(5,301-9,687)$ & $4,891(3,748-6,303)$ & $8,506(4,871-8,605)$ \\
$96 \mathrm{~h}$ & $2,879(2,196-3,562)$ & $7,372(6,292-8,461)^{* * *}$ & $4,838(3,963-8,047)^{* * * *}$ & $6,151(4,593-7,709)^{* * *}$ \\
$\mathrm{lL}-8, \mathrm{pg} / \mathrm{mL}$ & & & & \\
$6 \mathrm{~h}$ & $1,318(1,020-1,617)$ & $1,706(1,018-1,956)$ & $1,696(1,286-1,941)$ & $2,216(2,110-2,323)^{* * * * *}$ \\
$24 \mathrm{~h}$ & $1,266(996-1,536)$ & $1,177(767-1,608)$ & $1,224(799-1,706)$ & $2,187(2,119-2,254)^{* * * * *}$ \\
$48 \mathrm{~h}$ & $1,091(760-1,423)$ & $1,455(765-1,523)$ & $1,037(788-1,169)$ & $2,036(1,922-2,150)^{* * * *}$ \\
$72 \mathrm{~h}$ & $965(579-1,351)$ & $1,472(377-1,633)$ & $945(682-1,163)$ & $1,935(1,775-2,096)^{* * * * *}$ \\
$96 \mathrm{~h}$ & $981(482-1,481)$ & $464(244-1,127)$ & $690(288-1,005)$ & $1,859(1,775-1,943)^{* * * * *}$ \\
VEGF, pg/mL & & & & \\
$6 \mathrm{~h}$ & $72(34-110)$ & $343(290-508)^{* * *}$ & $297(145-504)^{* * * *}$ & $566(153-879)^{* * * *}$ \\
$24 \mathrm{~h}$ & $123(18-228)$ & $188(115-284)$ & $279(77-445)$ & $382(107-745)$ \\
$48 \mathrm{~h}$ & $121(20-221)$ & $123(95-172)$ & $283(84-435)$ & $123(54-406)$ \\
$72 \mathrm{~h}$ & $142(17-267)$ & $143(112-214)$ & $294(116-382)$ & $123(39-406)$ \\
$96 \mathrm{~h}$ & $144(8-280)$ & $134(115-336)$ & $280(191-425)$ & $280(81-445)$ \\
\hline A0 & & & &
\end{tabular}

A0: no rejection; $A 1$ : minimal rejection; $A 2$ : mild rejection; and A3: moderate rejection. ${ }^{\text {a } V a l u e s ~ e x p r e s s e d ~ a s ~ m e d i a n ~}$ (interquartile range). ${ }^{*} p<0.05$ (A3 > A0 and A1). ${ }^{* *} p<0.05$ (A3 > A0). ${ }^{* * *} p<0.05$ (A3, A2, and A1 > A0). ${ }^{* * * *} p<$ 0.05 ( $\mathrm{A} 3>\mathrm{A} 2, \mathrm{~A} 1$, and $\mathrm{A} 0)$. 
lymphatic vessels are cut, the amount of interstitial fluid leaving the lungs and going through the visceral pleura increases. This can lead to high cytokine levels, which have been observed in patients with graft rejection.

One limitation of the present study was the small number of patients in each subgroup. However, it is clear that inflammatory cytokine levels were highest in the patients in whom the severity of rejection was classified as A3. The lack of a significant difference between subgroups $A 1$ and $A 2$ regarding cytokine levels is possibly due to the small sample size. In addition, the fact that pleural fluid collection and TBB occurred at different time points possibly influenced the results. The data presented here are old, and a larger study, based on these data, is currently under way.

The present study demonstrated that elevated levels of proinflammatory cytokines in the pleural fluid of lung transplant recipients can be markers of acute graft rejection (particularly of moderate to severe rejection). In this context, determination of cytokine levels in pleural fluid can be useful in identifying patients who will develop graft rejection. Therefore, treatment can be initiated sooner, thus reducing lung parenchymal injury.

\section{Acknowledgments}

We would like to thank Dr. Richard W. Light for his assistance in developing the present study. This work was presented in abstract form at the Annual Congress of the European Respiratory Society, held in Barcelona, Spain, in 2010.

\section{References}

1. Martinu T, Howell DN, Palmer SM. Acute cellular rejection and humoral sensitization in lung transplant recipients. Semin Respir Crit Care Med. 2010;31(2):179-88. http:// dx.doi.org/10.1055/s-0030-1249113

2. Hoffman SA, Wang L, Shah CV, Ahya VN, Pochettino $\mathrm{A}$, Olthoff $\mathrm{K}$, et al. Plasma cytokines and chemokines in primary graft dysfunction post-lung transplantation. Am J Transplant. 2009;9(2):389-96. http://dx.doi. org/10.1111/j.1600-6143.2008.02497.x

3. Teixeira RH, Antonangelo L, Vargas FS, Caramori ML, Afonso JE Jr, Acencio MM, et al. Cytokine profile in pleural fluid and serum after lung transplantation. Transplant Proc. 2010;42(2):531-4. http://dx.doi.org/10.1016/j. transproceed.2010.01.033

4. Mathur A, Baz M, Staples ED, Bonnell M, Speckman JM, Hess PJ, et al. Cytokine profile after lung transplantation: correlation with allograft injury. Ann Thorac Surg. 2006;81(5):1844-9; discussion 1849-50.

5. Mal H, Dehoux M, Sleiman C, Boczkowski J, Lesèche G, Pariente R, et al. Early release of proinflammatory cytokines after lung transplantation. Chest. 1998;113(3):645-51. http://dx.doi.org/10.1378/chest.113.3.645

\section{About the authors}

\section{Priscila Cilene León Bueno de Camargo}

Pulmonologist. Department of Pulmonology, Heart Institute, University of São Paulo School of Medicine Hospital das Clínicas, São Paulo, Brazil.

\section{José Eduardo Afonso Jr}

Attending Physician. Department of Pulmonology, Heart Institute, University of São Paulo School of Medicine Hospital das Clínicas, São Paulo, Brazil.

\section{Marcos Naoyuki Samano}

Attending Physician. Department of Thoracic Surgery, Heart Institute, University of São Paulo School of Medicine Hospital das Clínicas, São Paulo, Brazil.

\section{Milena Marques Pagliarelli Acencio}

Head Biologist. Laboratory for Pleural Studies, Heart Institute, University of São Paulo School of Medicine Hospital das Clínicas, São Paulo, Brazil.

\section{Leila Antonangelo}

Head Physician. Department of Cytology, Central Laboratory, University of São Paulo School of Medicine Hospital das Clínicas, São Paulo, Brazil.

\section{Ricardo Henrique de Oliveira Braga Teixeira}

Clinical Coordinator. Lung Transplant Group, Heart Institute, University of São Paulo School of Medicine Hospital das Clínicas, São Paulo, Brazil. 